\title{
Material Flow Analysis: Outcome Focus (MFA:OF) for Elucidating the Role of Infrastructure in the Development of a Liveable City
}

\author{
Susan Lee, Joanne Leach, Dexter Hunt and Chris Rogers \\ School of Civil Engineering, University of Birmingham, UK
}

\begin{abstract}
Engineered infrastructures (i.e., utilities, transport \& digital) underpin modern society. Delivering services via these is especially challenging in cities where differing infrastructures form a web of interdependencies. There must be a step change in how infrastructures deliver services to cities, if those cities are to be liveable in the future (i.e., provide for citizen wellbeing, produce less $\mathrm{CO} 2$ \& ensure the security of the resources they use). Material Flow Analysis (MFA) is a useful methodology for understanding how infrastructures transfer resources to, within and from cities and contribute to the city's metabolism. Liveable Cities, a five-year research programme was established to identify \& test radical engineering interventions leading to liveable cities of the future. In this paper, the authors propose an outcome-focussed variation on the MFA methodology (MFA: OF), evidenced through work on the resource flows of Birmingham, UK. These flows include water, energy, food \& carbon-intensive materials (e.g., steel, paper, glass), as well as their associated waste. The contribution MFA: OF makes to elucidating the interactions \& interdependencies between the flows is highlighted and suggestions are made for how it can contribute to the (radical) rethinking of the engineered infrastructure associated with such flows.
\end{abstract}

Keywords: Urban Metabolism, MFA, Liveable Cities, Resource Flows, Infrastructure

\section{INTRODUCTION}

Engineered infrastructures (e.g., water, electricity, transport and digital) underpin modern society. Delivering services via such infrastructures is especially challenging in cities where different types of infrastructures are interlinked and intertwined, forming a complex web of (inter)dependencies. Yet this challenge must be addressed as the world becomes increasingly urbanised. Allied to this, cities are vast consumers of resources (e.g., water, energy and food), producers of waste and emitters of pollutants (including $\mathrm{CO}_{2}$ ). There must be a step change in how infrastructures deliver services to cities if those cities are to be liveable in the future (i.e., provide for the wellbeing of their citizens, operate in a low carbon manner and ensure the security of the resources they use).

Infrastructure is defined as "the basic physical and organizational structures and facilities (e.g. buildings, roads, power supplies) needed for the operation of a society or enterprise" ${ }^{\prime \prime}$. However, this definition has expanded over recent years to encompass green infrastructure (a network of green and environmental features) as well as digital infrastructure (storage and exchange of data) and social infrastructure (facilities that contain health, education and public services). This paper considers all aspects of infrastructure related to the flows of water, energy, food, carbon-intensive materials (e.g., steel, paper, glass) and people, as well as associated waste, into, within and out

1 Oxford English Dictionary. Definition of infrastructure in English, <http://tinyurl.com/n5jp88z > (2014). 
of the city of Birmingham, UK. The authors employ a newly-devised variation of the Material Flow Analysis (MFA) methodology (Material Flow Analysis: Outcome Focus (MFA:OF)) for understanding the city's flows, their relationship with engineered infrastructures and their contribution to the city's metabolism. This work has been carried out as part of the Liveable Cities Programme, a five-year interdisciplinary research programme combining the Universities of Birmingham, Lancaster, Southampton and UCL. Liveable Cities aims to identify and test radical engineering interventions that will lead to liveable cities of the future. The Programme includes stakeholders from an array of backgrounds who are interested in city operations and who are able to provide useful insights and feedback to Liveable Cities. These stakeholders include architects, city councils, environmental consultancies and agencies, utilities, urban designers, and sustainable development consultancies. The contribution MFA:OF makes to elucidating the interactions and interdependencies between the flows is highlighted and suggestions for how MFA:OF can contribute to the (radical) rethinking of the engineered infrastructure associated with such flows are made.

\section{URBAN METABOLISM AND MATERIAL FLOW ANALYSIS: OUTCOME FOCUS}

Urban Metabolism studies the resource flows in and out of a city system from a biological perspective ${ }^{2,3}$. This means that the city is seen as a living organism that is constantly evolving and reorganising. It largely extracts resources from beyond its boundaries, uses them within its boundaries to support city activities, and then deposits the resulting wastes back into the external environment. This is defined as linear metabolism 4 . This differs from the circular metabolism of a natural ecosystem, which produces no waste and survives off its immediate environment ${ }^{5}$. There have been numerous studies across the world using the methodology of urban metabolism focusing on the national and regional level 6,7, but fewer at a city level and even fewer looking at cities in the UK. In the last 15 years there have been six previous UK city studies: Manchester ${ }^{8}$, Liverpool ${ }^{9}$, York ${ }^{10}$ and London ${ }^{11,12,13}$. In addition, more recent work was carried out on the city of Birmingham by the Stockholm Environment Institute through their Resources and Energy Analysis Programme (REAP) ${ }^{14}$.

Material Flow Analysis (MFA) was a widely adopted approach used in the urban metabolism studies of UK cities. MFA has traditionally focussed on flows of materials, although such an object-focussed analysis risks oversimplifying the complex qualities of cities. The authors argue that an outcome-focussed analysis; for example, selecting flows and units of measure relevant to a desired outcome, provides a more nuanced picture and allows for the identification of infrastructure interactions, interdependencies and interrelationships, as well as incorporating economic, social, cultural and environmental priorities. Even so, additional information is required for a full city analysis (e.g., consideration of the temporal nature of the city's resource flows).

2 Barles, S. Urban Metabolism of Paris and Its Region. Journal of Industrial Ecology 13 (2009)

3 Ferrao, P. \& Fernandez, J. E. Sustainable Urban Metabolism. (MIT Press, 2013).

4 Costa, A., Marchettini, N. \& Facchini, A. in The Sustainable City III. (ed N. Marchettini, Brebbia, C., Tiezzi, E. \& Wadhwa, C.) (WIT Press, 2004).

5 Girardet, H. Cities People Planet - liveable cities for a sustainable world. (Wiley Academy, 2004).

6 Kennedy, C., Steinberger, J., Gasson, B., Hillman, T., Havránek, M. Hansen, Y., Pataki, D., Phdungsilp, A., Ramaswami, A., Villalba Mendez, G. Greenhouse gas emissions from global cities Environmental Science and Technology 43 7297-7302 (2009).

7 Muukkonen, J. TMR, DMI and material balances, Finland 1980-1997. (Luxembourg, 2000).

8 Douglas, I., Hodgson, R. \& Lawson, N. Industry environment and health through 200 yrs in Manchester. Ecological Economics 41 , 235-255 (2002).

9 Barrett, J. \& Scott, A. An Ecological footprint of Liverpool: Developing sustainable scenarios. A detailed examination of Ecological Sustainability, <http://www.gdrc.org/uem/footprints/LiverpoolEFReport.PDF> (2001).

10 Barrett, J., Vallack, H., Jones, A., Haq, G. A Material Flow Analysis and Ecological Footprint of York. (Stockholm, Sweden, 2002).

11 Best Foot Forward Ltd. City Limits Report. A resource flow and ecological footprint analysis of Greater London, <http://tinyurl.com/ qjkumxl> (2002).

12 Greater London Authority (GLA). London's Ecological Footprint. A review, <http://tinyurl.com/qjkumxl> (2003).

13 Nates, M., Bartlett, J. \& Kirkpatrick, N. Feasibility study to examine making the Thames Gateway a low carbon/carbon neutral development area, <http://www.communities.gov.uk/documents/thamesgateway/pdf/1074136.pdf> (2008).

14 Stockholm Environmental Institute (SEl). An Introduction to the Resources and Energy Analysis program, <http://tinyurl.com/mnjbbnt> (2007). 


\section{METHODOLOGY}

The Liveable Cities Programme was established in 2012 to identify and test radical engineering interventions that would lead to liveable cities of the future. Such cities would be low carbon, resource-secure and provide a city environment in which societal wellbeing would be (at least) maintained and preferably enhanced. These are the programme's desired outcomes for cities. To identify how a city operates, three UK case study cities were selected to represent a range of locations and sizes: Birmingham, Lancaster and Southampton. Birmingham provided the original test bed, the learnings from which could then be applied to the other two cities having identified any gaps or shortcomings prior to applications further afield. MFA was selected as the most robust methodology for mapping resource flows at the city scale. Taking into account the programme's desired outcomes (low carbon, resource security, high wellbeing), six resource flows relevant to these outcomes and important to the operation of the city were identified: water, energy, food, carbon-intensive materials (steel; aluminium; cement; plastic; paper; glass; and sand, gravel \& aggregates), people and waste. Importantly, the carbon associated with these flows was identified as well as raw movement data. Data sources and availability were also identified, with the intention that these sources were as accessible as possible.

The analysis had three primary objectives: (i) to establish a current baseline for Birmingham in terms of resource movement and carbon; (ii) to establish a desired state for Birmingham in 2050 in relation to these resources, and (iii) to inform radical re-thinking of the underpinning infrastructures and service provision mechanisms in order to develop a strategy for achieving the desired 2050 end state. The analysis was not intended to be a full MFA of the city.

\section{BIRMINGHAM: A SNAPSHOT}

\section{Water}

- Sources and related infrastructures: the vast majority of Birmingham's water is supplied to the city via a pipeline from the Elan Valley in Wales (some 73 miles away). This delivers around $345 \mathrm{Ml} /$ day to the city. This water is stored in a number of reservoirs around the city.

- Demand: 83,000 Ml/yr.

- Waste: $182,500 \mathrm{Ml} / \mathrm{yr}$.

- Associated carbon emissions: $85 \mathrm{ktCO}_{2} / \mathrm{yr}$.

- These figures are calculated from Severn Trent Water data ${ }^{15}$.

\section{Energy}

- Sources and related infrastructures: The National Grid supplies gas and electricity to the city via the "Big Six" energy companies. Diesel and petrol are sourced via oil refineries. In 2011, 26\% of Birmingham's energy demand was supplied via domestic gas from the North Sea. Local energy (Combined Heat and Power, and District Heating) provides the city with 81 GWh per year along with 217 GWh from the Tyseley Energy from Waste Plant (2\% of the city's energy consumption).

- Demand: There is a high demand for energy given that Birmingham is the second largest city in the UK and home to 1.07 million of people ${ }^{16}$ (ONS, 2012). In 2011, the total energy consumed by the city was 1.66 Mtoe.

- Waste (Heat energy): $3.5 \mathrm{GW}$ of heat.

- Associated carbon emissions in 2011: $2193 \mathrm{ktCO}_{2}$ (industry and commercial); $1891 \mathrm{ktCO}_{2}$ (domestic); $1405 \mathrm{ktCO}_{2}$ (transport).

15 Severn Trent Water. Water Resources Management Plan Final Version. June 2010, <http://www.stwater.co.uk/about-us/our-businessand-strategy/water-resources-plan/> (2010).

16 Office for National Statistics (ONS). 2011 Census, Population and Household Estimates for the United Kingdom, <http://www.ons.gov. uk/ons/rel/census/2011-census/population-and-household-estimates-for-the-united-kingdom/index.html> (2012). 


\section{Food}

- Sources and related infrastructures: The food supplies to the city are mostly imported from within the UK (just over 50\%), with $28 \%$ from the EU and the remainder from the rest of the world ${ }^{17}$.

- Demand: The average Birmingham citizen consumes $3400 \mathrm{kcal}$ a day, more than $1400 \mathrm{kcal}$ above the average recommended Guideline Daily Amount for an adult. 25\% of the population in the city is obese, the third highest rate in the UK, and that $40 \%$ of children aged 11 are overweight or obese ${ }^{18}$. Birmingham citizens buy $368 \mathrm{kt}$ of food and $288 \mathrm{Ml}$ of drink (excluding water) per year, spending £2.1 billion per year ${ }^{19}$.

- Waste: $155 \mathrm{kt}$.

- Associated carbon footprint: $354 \mathrm{ktCO}_{2}$ (freight transport which includes food transfers).

\section{Carbon-intensive materials}

- Sources and related infrastructures: The city produces nearly $8 \mathrm{Mt}$ of manufactured goods. In addition, over twothirds of the materials are imported (15 Mt). These imports consist of $11.6 \mathrm{Mt}$ from within the UK (75\%) and 3.7 Mt from the rest of the world (including 0.5 Mt of metals)20. Around half of the UK imports are from the paper and publishing industry together with the food, beverages and tobacco industry. Birmingham exports 11.8 million tonnes of manufactured goods, of which car exports make up around 8\%21.

- Demand: Around 10 million tonnes of carbon intensive materials are consumed by the city 19.

- Waste: (Industrial and commercial) 967 kt (2006/2007).

- Associated carbon footprint: 1891 ktCO2.

\section{People}

- Sources and related infrastructures: There are 313,250 commuters coming into Birmingham every weekday; $62 \%$ of these live within the city boundaries, with 29\% coming from local towns including Coventry, Tamworth and Wolverhampton. The remaining 11\% come from further afield (extending as far as the Isle of Wight and Anglesey) ${ }^{22}$. Around $60 \%$ of commuters travel by car, while $18 \%$ travel by bus, $10 \%$ by walking, $5 \%$ travel by train, 2\% cycle, with the remaining 5\% using other means (including mopeds, scooters, motorbikes, taxi) ${ }^{23}$.

- Associated carbon emissions: $1405 \mathrm{ktCO}_{2}$.

\section{$\mathrm{CO}_{2}$ Emissions}

- In 2012, Birmingham emitted $5.6 \mathrm{Mt} \mathrm{CO}_{2}$ - about 42\% came from the commercial sector which includes industry, $37 \%$ from domestic buildings and the remaining $21 \%$ from transport.

17 Department for Environment Food and Rural Affairs (DEFRA). Food Statistics Pocketbook 2013, <https://www.gov.uk/government/ publications/food-statistics-pocketbook-2013> (2013).

18 Centre for Obesity Research. Obesity in the UK, <http://tinyurl.com/moxuq7t> (2014).

19 Department for Environment Food and Rural Affairs (DEFRA). Family Food 2012, <http://tinyurl.com/kfgfyw7> (2012).

20 WWF. Counting consumption. CO2 emissions, material flows and Ecological Footprint of the UK by region and devolved country. (2006).

$21 \mathrm{HM}$ Revenue and Customs. UK overseas trade statistics and regional trade statistics, <http://tinyurl.com/oal2q8p> (2014).

22 Office for National Statistics (ONS). Annual Population Survey commuter flows, local authorities in Great Britain, 2010 and $2011,<$ http:// tinyurl.com/lqypx3u> (2013). 


\section{BIRMINGHAM: THE FUTURE}

The Liveable Cities Vision prioritises a move towards a low carbon, resource secure city where the well-being of its citizens is enhanced or improved. Future city visions are being developed centred around the well-being of citizens. Such visions provide principles which cities can aim towards. When applied to a city, these principles inspire design concepts and ideas. Considering the principle of open public space, this requires designs that incorporate openness, availability and accessibility. Each of these has its own requirements. For example, accessibility requires geographical and temporal access for all people. Public transportation is one way of achieving this. Applied to Birmingham this might result in an extended city-centre tram system ${ }^{23}$, while applied to Medellin, Colombia this might result in cable cars $^{24}$, the point here being that each city provides its own unique context and the resulting engineered solutions must reflect that context. Put another way, adopting a tram system as a universal solution to the problems of people movement would be a poor approach (and in fact, an unworkable solution in Medellin), whereas universal adoption of the guiding principle has merit. In all cases it is readily apparent that for visions to become reality, cities need to consider how existing flows might change, or how they could/should be modified (now and in the future) and what impact this would have on a city's liveability. MFA:OF provides part of the necessary evidence base; in the case of Liveable Cities, this involves selecting flows important for resource security and linking them to carbon if we are to meet the primary programme aims, and in parallel assessing them for a wider set of city performance parameters that encompass wellbeing, resource security, carbon, governance and economics. Inevitability, tensions will arise caused by interactions between flows. For example, in Birmingham if food waste is reduced this will impact on the amount of waste burnt by the incinerator in the energy from waste scheme and reduce energy production.

Designing to well-being principles cannot be done at the expense of a city's resource security or its carbon emissions, and many factors come into play. For instance, we might be forced to reduce the amount of allowable water usage per person, due to the combined effects of reduced availability and an expanding 'demand driven' population. If so, what impact might this have on our citizens and how can this be made more acceptable? What policies would be required? What would be the cost (to the economy and the environment) and what interventions in terms of solutions (existing or innovative) or transformative approaches might be required?

\section{CONCLUSION}

Infrastructure is a vital part of our cities. Well-being is paramount for successful cities, but with increasing resource scarcity and the impacts of climate change it is time for cities to use such resources in the most efficient and lowest carbon way possible. Material Flow Analysis: Outcome Focus (MFA:OF) provides part of the required (and currently lacking) evidence capable of tying together these outcomes. By its nature, the implications for engineered infrastructures are made explicit and the opportunities for infrastructure to create liveable cities elucidated. The mechanisms for achieving a liveable city are necessarily varied, incorporating 'push' actions, such as higher energy costs, and 'pull' actions, such as aspirations for a better future. In addition, education, taxes, and incentives will contribute to behavioural change. In the UK, this will likely require funding and/or legislation from Government or the European Union to drive things forward. There is also a need to involve SMEs and industry. Good case studies and new methodologies, such as that of Birmingham and MFA:OF provided by the Liveable Cities team, will provide guidance and inspiration for cities to achieve the necessary carbon and waste reductions and resource efficiencies without compromising (and hopefully increasing) the wellbeing of its citizens. In turn, these city needs and aspirations of the future, which necessarily prioritise wellbeing, are embraced in Liveable Cities' guiding principles, which are then applied (engineered) to each individual, unique city context.

23 Centro. Midland Metro, <https://www.centro.org.uk/transport/metro/> (2014).

24 Metro de Medellin. Metro Cable, <http://tinyurl.com/pajawxa> (2014). 